\title{
The Impact of Active Learning Strategies on Retention and Outcomes in Safety Training
}

\author{
Wanda Minnick, Tracey Cekada, Luz Marin, Majed Zreiqat, Bryan Seal, John Mulroy \\ Safety Sciences Department, Indiana University of Pennsylvania, Indiana, USA \\ Email: wanda.minnick@iup.edu
}

How to cite this paper: Minnick, W., Cekada, T., Marin, L., Zreiqat, M., Seal, B., \& Mulroy, J. (2022). The Impact of Active Learning Strategies on Retention and Outcomes in Safety Training. Creative Education, 13, 526-536.

https://doi.org/10.4236/ce.2022.132031

Received: December 23, 2021

Accepted: February 15, 2022

Published: February 18, 2022

Copyright (c) 2022 by author(s) and Scientific Research Publishing Inc. This work is licensed under the Creative Commons Attribution-NonCommercial International License (CC BY-NC 4.0). http://creativecommons.org/licenses/by-nc/4.0/

\begin{abstract}
Active learning strategies are generally accepted as a more effective means to increase and sustain students' learning, since these strategies involve the learner in doing, discovering and collaborating, all of which heightens the cognitive and social presence of the learner. There are few studies that examine outcomes and retention rates of participants in safety training generally, especially studies that compare traditional to active learning methods. The aim of this study was to examine student outcomes and retention rates between two groups of students who received a face-to-face 50-minute hazard communication training. One group of participants received training that used traditional lecture methods while the other group received training that incorporated active learning strategies. Participants were required to take a pre-test, post-test and retention test. The groups received the same training content, and the instruction was delivered by the same instructor team. The results of this pilot study revealed that students who received the traditional training tended to have higher scores immediately following the training, however one month following the training students receiving training that incorporated active learning strategies had higher total scores, suggesting active learning may assist with learning retention. The range of scores was more varied in the active learning group, with a larger range between the highest and lowest scores. The differences were not statistically significant which can be explained by the small sample size. Lessons learned are offered that can help inform the framework of a larger future study.
\end{abstract}

\section{Keywords}

Active Learning, Safety Training, Community of Inquiry (CoI), Retention

\section{Introduction}

Training in occupational risk prevention is an important issue, notably because 
it constitutes a prerequisite to improving health and safety in the workplace (Vidal-Gomel, 2017). In a recent study on training effectiveness among construction workers, it states that "safety training has been regarded as the most important factor in preventing safety accident hazards" (Ahn et al., 2020: p. 3). Likewise, in another study, it is suggested that ineffective training on construction sites is the leading cause of accidents (Poshdar et al., 2021). Additionally, the National Occupational Research Agenda (NORA) regularly calls for additional training or education research in the construction and manufacturing industries each year, with the year 2020 being no different (CDC, 2021). Training is imperative to any organizations safety and health management system, as it is a cross-cutting communication mechanism that at a minimum should create awareness of safety hazards in the workplace.

The need for effective safety training and learning transfer is essential to be able to recognize risk, be aware of hazards, and to perform one's job with competence. Studies that examine traditional and/or passive strategies, such as lecture, PowerPoint, or toolbox talks (Gao et al., 2019) and compare them to active learning strategies, such-as hands-on learning, collaboration and discovery, are limited in the safety sciences. However, it should be noted that there is a recent influx in studies that examine outcomes between training that uses virtual reality (VR), one type of active learning, and traditional delivery modes on construction and fire topics. The aim of this study was to examine retention rates and learning outcomes of participants that receive face to face safety training using traditional learning methods to those that receive safety training that incorporate active learning strategies.

\section{Instructional Design: Intentional Incorporation of Active Learning}

An active learning strategy is a method an Instructor incorporates that actively engages the students in contributing, collaborating, discussing, discovering, reflecting, and sharing. Incorporating active learning strategies into training and education has been suggested as a successful way to improve both knowledge and its application. Active learning can broadly be defined as methods that encourage active and cognitive engagement of students with the learning material (Wiederman, 2015). It has also been described as part of a constructivist framework (Anthony, 1996), as students become active in their learning by taking on new information that builds on previous knowledge (Padilla \& Kreider, 2018).

Simply, it is knowledge construction through participation. However, the incorporation of active learning strategies should be considered in tandem with motivation and instructional design. Creating a motivating learning environment for adult learning and training, requires thinking about what motivates adult learners. Using Vroom's Expectancy theory, this can be explored within three frames. Does the learner think they can achieve the outcome (confidence), does the learner think the outcome will lead to a desired result, and does the 
learner see valency (value) in the outcome (DuBrin, 2014). The somewhat subconscious and internal cost-benefit calculation that occurs results in the question What's In It For Me (WIIFM) and can influence the participant's motivation. Assuming that the first two pillars of Vroom's theory are met by the participant, creating value for the participant is in the product that the Instructor can provide. Specifically, will the Instructor provide the acquisition of new knowledge or new skills. However, participation and engagement are required in order to acquire them. Students must see the value of actively participating which is something the Instructor must intentionally consider through instructional design.

The instructional design of training has important implications for its effectiveness in terms of trainee knowledge, performance and retention. Previous studies on training design and delivery have indicated the positive results of active learning (Ricci et al., 2016; Middleton, 2013), although studies specific to the safety sciences exist, they are limited.

However, in a meta-analysis conducted by Gao et al. (2019) on the effectiveness of traditional tools (TT), such as lecture and toolbox talks, as compared to computer-aided technologies (CAT), in construction safety training suggests more research is needed. The CAT strategies included items like virtual Reality, mixed reality (MR), and simulations, and since these techniques engage the participant in discovery, they could be considered active learning strategies. The synthesized studies included effectiveness measures in terms of knowledge acquired, behaviors altered or injury reduction. The authors concluded that while TT typically equated to knowledge acquisition gains, they were unable to conclude that CAT strategies are more effective than TT because empirical research was limited, except for virtual reality (VR) which did indicate effectiveness in some studies. For example, several researchers that incorporated VR into fire related training concluded it is more effective than traditional methods (Lovreglio et al., 2021; Satapanasatien et al., 2021; Çakiroğlu \& Gökoğlu, 2019). However, an examination of traditional safety training to VR-based training in construction, observed no significant difference in risk identification or risk behavior between the two delivery methods (Poshdar, 2021: p. 471). Previous studies, not within the safety sciences discipline, that used more common active strategies, such as collaboration and discussion, have also reported effectiveness. One study considered retention rates among three groups of first year dental students that were exposed to three different course techniques (Ruest, 2017). They concluded a positive significant difference in retention of learned material for the group that used an active learning tool after a self-learning event compared to the other two groups.

Traditional lecture is a common method used in academia and industry when delivering recurring annual Occupational Safety and Health Administration (OSHA) required training or other topics. However, relying on one-way facilitator communication during training could hamper the potential of students, especially the ability to apply what they have learned. Placing emphasis on how the learner understands and thinks about the content helps transition to a more 
active approach. This approach has the potential to advance student learning, not only through fostering higher order thinking and learning skills, but also through promoting the ability to comprehend and apply knowledge to real-life situations (Traphagan, 2010).

\section{Study Design and Methodology}

This project examined the impact of active-learning methods on retention rates of students receiving training on a revised OSHA standard by comparing it to traditional teaching methods. This study used a similar design approach as Lovreglio et al. (2021) in their study that compared traditional training methods to a virtual reality training method, however in this study, a mixture of active learning techniques was included in the active learning session. Likewise, to their study, a pre-test, post-test and retention test were employed to test significance.

The content was consistent in both training types. The topic of the training was the revised Hazard Communication Standard (HCS), a topic that is regularly delivered in a passive lecture-based manner. The HCS ranked as the second most cited standard following workplace inspections by federal OSHA in 2020 (NSC, 2021). This lends support to the significance of studying how types of training delivery can best impact learning retention and transfer on this topic. The traditional training consisted of instructors delivering a modified version of a HCS PowerPoint available on the OSHA.gov website and a supplemental video. The active learning session included the same power-point presentation but intentionally emphasized the Community of Inquiry framework and its dimensions of teacher, social, and cognitive presence. Although the CoI is typically used in the design of on-line education, it has proven effectiveness for face-to-face learning as well (Warner, 2016). The active learning session encouraged questions and answers with the instructors emphasizing teacher presence. Students were also encouraged to interact with each other when looking up information on safety data sheets and transferring that information to a label, promoting both a social and cognitive presence. During the traditional training, interaction with the instructors was limited to receiving the lecture only. Social engagement through team activity was not provided. The same team of instructors delivered both training sessions to reduce instructor bias by standardizing the training delivery method.

\subsection{Participants}

University students without a safety and health background were recruited to participate in this study. Students were randomly divided into two groups; group one received traditional 50-minute face to face Hazard Communication Standard (HCS) training while group two received a 50-minute face to face active learning HCS training. Prior to receiving the training, participants from both groups were tested to evaluate their HCS knowledge using a pretest questionnaire. The students accessed the pretest questionnaire using Qualtrics on-line survey software. Immediately following the training, participants were given a 
Qualtrics post-test questionnaire with identical pre-test questions to answer. After one month, students were contacted via email and were asked to take a retention test, again using Qualtrics with the same questions. Students were given a \$15 Amazon gift card upon the completion of each test. Figure 1 illustrates the overall flow of the process. Both instructors who participated in the study had many years of experience teaching in a safety and health, active learning classroom environment using both traditional and active learning methods. Both covered the same content in each section with identical content.

\subsection{Data Analysis}

Descriptive statistics, such as the mean, standard deviation, frequency, and percentages were used to answer the following research questions:

RQ1: Will the average students' test score be higher for students who received the training with the active learning components when compared to those who received the traditional learning components immediately following the training?

RQ2: Will the total students' test score be higher for students who received the training with the active learning components when compared to those who received the traditional learning components one month following the training (retention)?

Repeated Measure Two-Way Analysis of Variance (ANOVA) was used to analyze the data. The dependent variable is the average test score which is a continuous variable. The independent variables are time, which is a nominal variable with three levels (pre, post and one month later) and training type which is nominal with two levels (traditional vs. active). Significance was determined using an alpha ( $\alpha$ ) of .05. Data was analyzed using SPSS software version 27.

\subsection{Results}

There were 19 participants, 10 in the traditional group and nine in the active

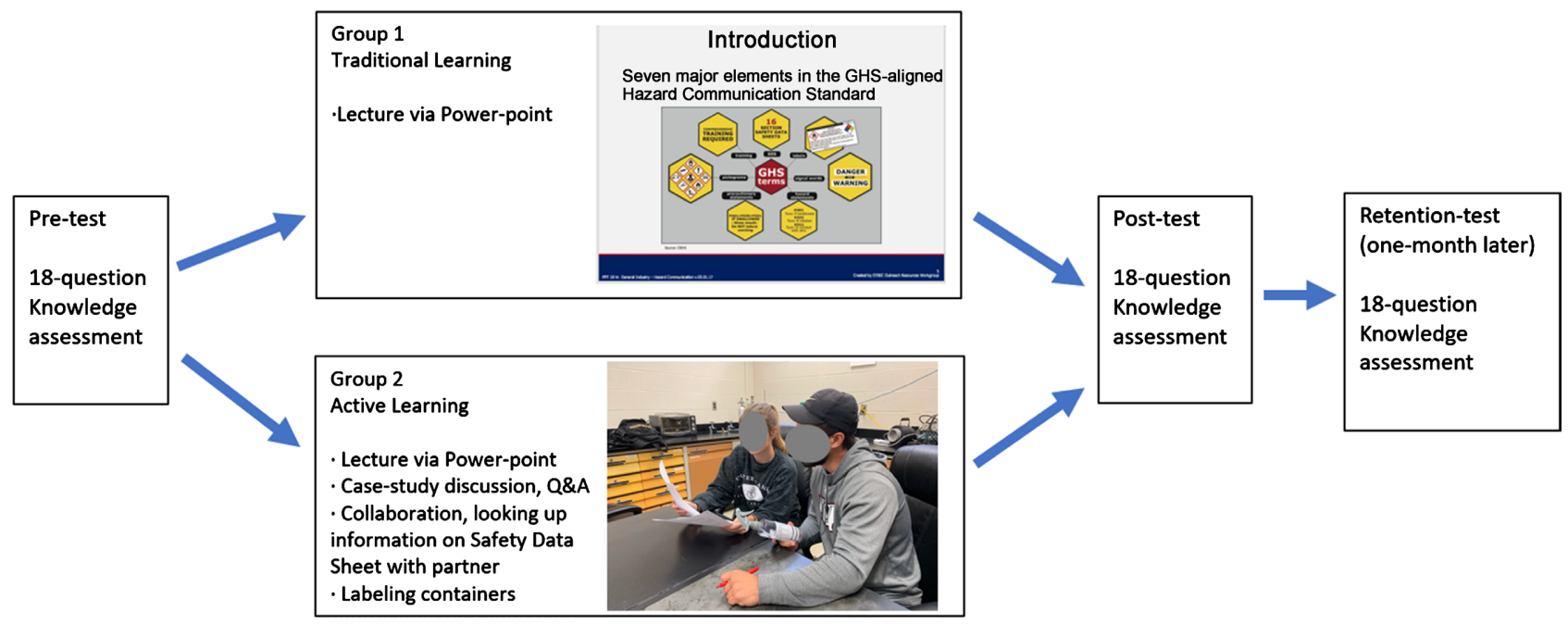

Figure 1. Process design flow. 
learning group. The same 18 questions were asked on the pre-test (immediately prior to the training), the post-test (immediately following the training) and the retention test (one month following the training). Participants' average pre-test scores for traditional and active delivery methods were similar (40.7 \pm 17.3 and $39.7 \pm 18$, respectively; $p>.05$ ). However, the one-month follow-up (retention) test showed that the average score decreased $21 \%$ (17.6 points) in the traditional group in comparison to the post-test while the reduction in those participants who attended active training sessions was $6.5 \%$ (4.8 points). In the follow-up test, participants in the active learning methods scored slightly higher, though not significant, than those in the traditional group $(64.8 \pm 19.9$ and $68.3 \pm 28.4$, respectively; $p>.05$ ). Figure 2 illustrates the total point comparison between traditional training and active learning training.

Figure 3 represents the trend in scores by delivery method. Participants in the active learning group generally had less differences between post and follow up test scores and, in general, higher variability among scores was identified among those in the active learning strategies.

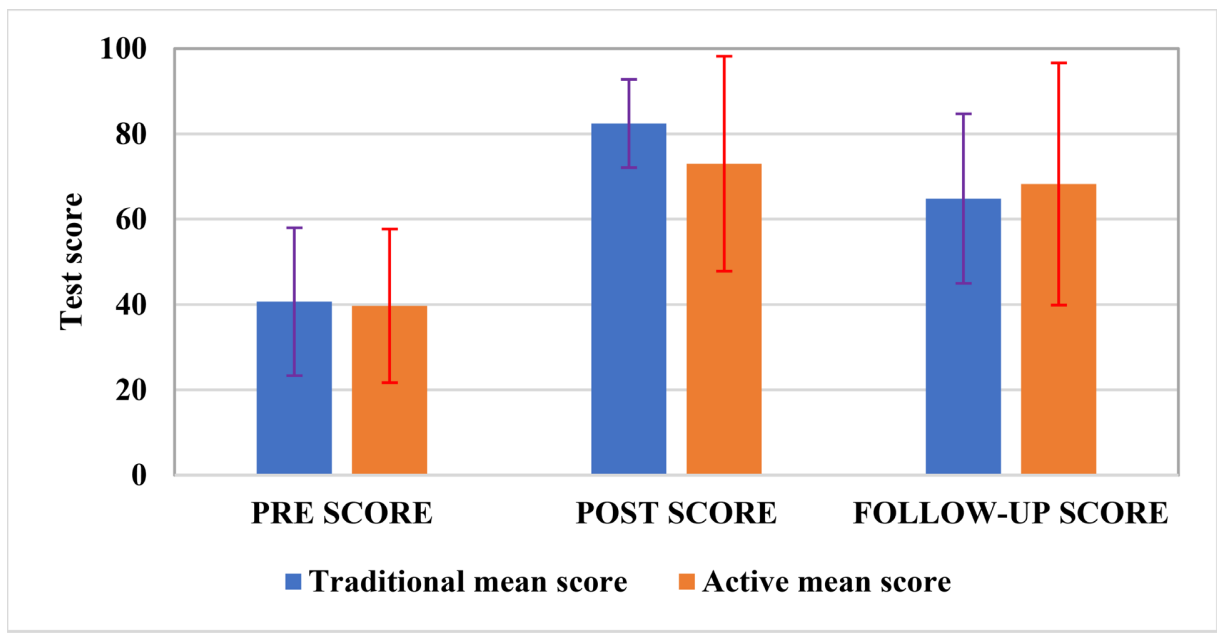

Figure 2. Total point comparison between traditional and active learning training.

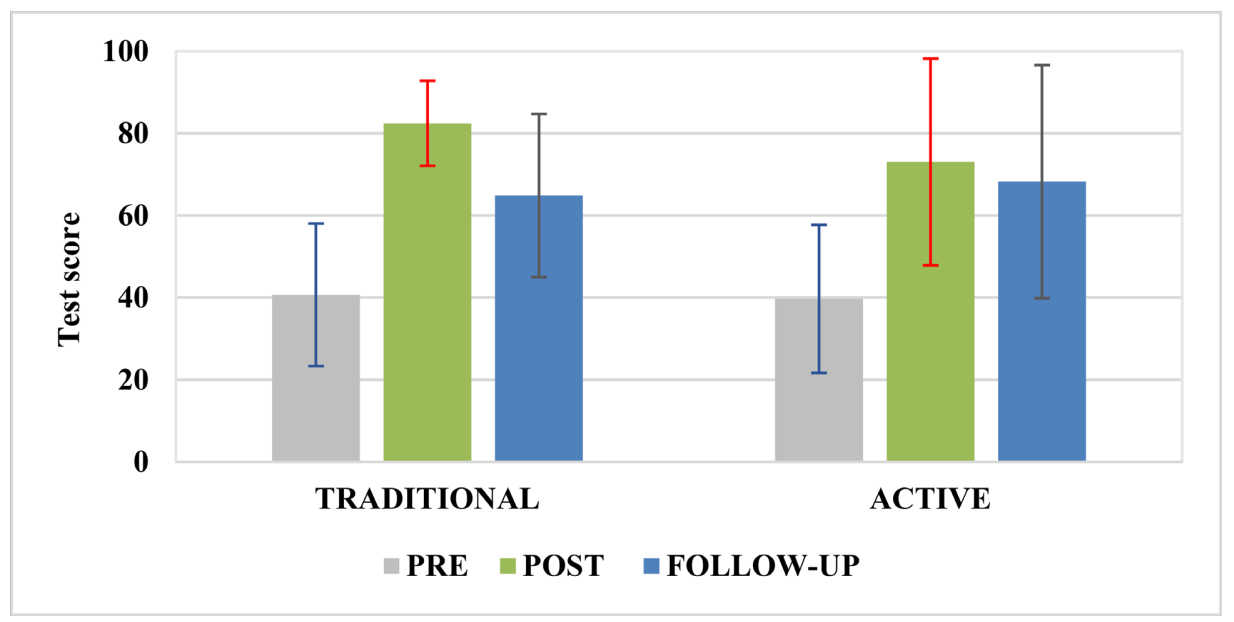

Figure 3. Average score trends in each delivery methods. 


\subsection{Lessons Learned}

The lessons learned from the pilot study will be important when designing a future larger study. Future study design should take into consideration the possibility for students to look up answers on-line during all testing, therefore actual testing would need to be taken in a secure environment or the questions would need to be applied in nature. Memorization of questions could be a potential source of bias in this type of study, meaning the same questions were asked during the pre-test, post-test, and retention-test. This could have resulted in the participant either memorizing questions and looking them up after one test and prior to the next, or they could quickly answer the same way they did in prior tests. Lastly, offering an incentive could encourage haphazardly taking the test just to get the reward. The methodology of a future and larger study would need to address these concerns.

\section{Discussion}

The results of the pilot study, although not statistically significant, indicated that participants who received the traditional training tended to have higher average test scores immediately following the training, however one month following the training participants in the active training group had slightly higher test scores, suggesting active learning may assist better with learning retention than traditional learning. Both groups performed similarly on the pre-test questionnaire indicating there was no bias in baseline knowledge prior to the test.

Due to the engaging nature of the training that the active group received, it was hypothesized this group would score better on both the post-test and the retention test. Interestingly, participants in the traditional training scored higher on the post-test immediately following the training. This could be explained by nature of the training content. The Hazard Communication training was introductory in nature and was teaching basic definitions and light hands-on skills (e.g., labeling and looking up information as a team). It is plausible that the material content may influence which delivery method is most effective. However, when comparing retention-test scores one month later, the participants from the active learning group scored higher, suggesting that the more engaging class assists in retention. This is similar to the results of a meta-analysis (Burke et al., 2006) of 95 studies that examined training in relevant fields and their outcomes, such as knowledge acquisition and safety performance. The researchers concluded that "the more engaging a method of training, the greater the effects of safety and health training on knowledge acquisition" (p. 318). Also, noteworthy is the range of test scores between the two groups. Participants in the active learning training had a larger score range than those in the traditional learning group, suggesting other variables could contribute to both outcomes and retention. Those variables could be informed by a recent publication that reviewed studies from 2010 to 2020 and suggests that learning transfer is influenced by variables such as pre-training, contextual, and organizational factors. Motivation 
to learn, for example, is a pre-training state that can result in "greater retention of knowledge, greater uptake of attitudinal change, and higher intention to engage in learned behaviors" (Casey et al., 2021: p. 305). The contextual state, such as if the training is voluntary or mandatory, and its perceived relevance can also influence learning transfer as well as organizational factors, such as safety climate. Student interest in the material (perceived relevance) or motivation is variables needing further examination (Riener \& Willingham, 2010). Additionally, the participant's preference in how to receive the learning is of importance because it could change dependent on the training topic and could impact overall results (Pashler et al., 2008).

The modality utilized for this study was face to face. Advancements in on-line technology and the increased familiarity with on-line learning is driving educators to identify the appropriate mix of traditional and active approaches in tandem with their effectiveness in varying modalities. The on-lines modalities are sometimes "labeled" differently, but are most termed web-based, hybrid, blended, synchronous, or asynchronous and are described in Table 1. Likewise, to the increased variability in modalities are the increased variability in active learning approaches, such as gamification and virtual reality. However, many studies have only examined the use of gamification or VR as the 'sole' delivery method versus a traditional format instead of considering them as a supplement to other active strategies or traditional methods. The approaches used in this study are italicized.

Table 2 indicates traditional approach strategies and active learning strategies including more recent formats. The italicized items indicate the methods employed in this study.

Table 1. Descriptions of common modality types.

\begin{tabular}{ll}
\hline Modality Type & Description \\
\hline Traditional Face to Face & $\begin{array}{l}\text { Instructor and participants meet in person at a regular } \\
\text { scheduled time in the same physical space. }\end{array}$ \\
On-line Synchronous & $\begin{array}{l}\text { Instructor and participants meet at a regular schedule time } \\
\text { on-line. }\end{array}$ \\
On-line Asynchronous & $\begin{array}{l}\text { Self-paced, instructor and participant interactions occur (e.g., } \\
\text { discussion threads and pre-recorded lectures) without } \\
\text { required meeting times. }\end{array}$ \\
Web-based & $\begin{array}{l}\text { Self-paced, participant completes the learning event with little } \\
\text { to no instructor or peer student interaction. }\end{array}$ \\
Hybrid Synchronous & $\begin{array}{l}\text { Participants have the option to attend face to face in the same } \\
\text { physical space } \text { or attend on-line during the regular schedule } \\
\text { time for the class. }\end{array}$ \\
Blended Synchronous & $\begin{array}{l}\text { The course it designed so that it requires a blend of } \\
\text { attendance, some dates the instructors and the participants are } \\
\text { required to meet synchronously on-line and on other dates } \\
\text { require meeting face to face in the same physical space. }\end{array}$ \\
\hline
\end{tabular}


Table 2. Traditional and active learning techniques.

\begin{tabular}{ll}
\hline Traditional Learning & Active Learning \\
\hline - Lecture & - Collaboration \\
- Powerpoint & - Discussion (case studies, questions, answers) \\
- Toolbox Talks & - Using hands-on activities (examining, building, \\
& identifying, auditing, labeling, looking up information) \\
- PassiveVideo Watching & - Gamification \\
- Brochures & - Virtual Reality \\
- Pocket-Cards & - Group annotation (schematics, drawings, articles, \\
& diagrams)
\end{tabular}

There is a need for more research that measures the long-term efficacy, competency, and retention rates for safety training that includes a mix of active learning strategies and in different modalities. Additionally, recent research has supported exploring other variables such as motivation to learn, perceived relevance, and preferred learning style for the topic. The prevalence of on-line learning is pushing trainers and educators to identify active training methods that can be delivered virtually and effectively. Considering the inherent obligation to deliver safety training with methods that result in competency, studies that compare skills taught in a face-to-face modality to skills taught in a web-based and/or hybrid modality are warranted.

\section{Conclusion}

The results should be interpreted with caution due to the low sample size. The results of this pilot study revealed that students who received the traditional training tended to have higher scores immediately following the training, however one month following the training students receiving training that incorporated active learning strategies had a higher mean score, suggesting active learning may assist with learning retention. The range of scores was greater in the active learning group than the traditional learning group. A future study that compares training delivery methods, such as active versus traditional, on student learning outcomes and retention rates in varying online modalities, such as synchronous, asynchronous and blended/hybrid settings should be considered using the lessons learned from this study. Additional research is also needed on how to best incorporate active learning into on-line modalities that are beneficial for a large range of audiences that consider variables, such as the training topic, the learner motivation, and learner preference.

This study assessed retention based on active learning strategies using a randomized experimental approach and identical course materials. Faculty or trainers implementing active classroom strategies should consider the effect in retention that these strategies may provide to the students, considering the skills and abilities that the student may require in the short-, medium-, and long-term 
once they conclude their academic preparation.

\section{Conflicts of Interest}

The authors declare no conflicts of interest regarding the publication of this paper.

\section{References}

Ahn, S., Kim, T., Park, Y. J., \& Kim, J. M. (2020). Improving Effectiveness of Safety Training at Construction Worksite Using 3D BIM Simulation. Advances in Civil Engineering, 2020, Article ID: 2473138. https://doi.org/10.1155/2020/2473138

Anthony, G. (1996). Active Learning in a Constructivist Framework. Educational Studies in Mathematics, 31, 349-369. https://doi.org/10.1007/BF00369153

Burke, M. J., Sarpy, S. A., Smith-Crowe, K., Chan-Serafin, S., Salvador, R. O., \& Islam, G. (2006). Relative Effectiveness of Worker Safety and Health Training Methods. American Journal of Public Health, 96, 315-324.

Çakiroğlu, Ü., \& Gökoğlu, S. (2019). Development of Fire Safety Behavioral Skills via Virtual Reality. Computers \& Education, 133, 56-68.

https://doi.org/10.1016/j.compedu.2019.01.014

Casey, T., Turner, N., Hu, X. W., \& Bancroft, K. (2021). Making Safety Training Stickier: A Richer Model of Safety Training Engagement and Transfer. Journal of Safety Research, 78, 303-313. https://doi.org/10.1016/j.jsr.2021.06.004

Centers for Disease Control (CDC) (2021). National Occupational Research Agenda. https://www.cdc.gov/nora/comment/agendas/default.html

DuBrin, A. J. (2014). Human Relations: Interpersonal Job-Oriented Skills (12th ed.). Pearson.

Gao, Y., Gonzalez, V. A., \& Yiu, T. W. (2019). The Effectiveness of Traditional Tools and Computer-Aided Technologies for Health and Safety Training in the Construction Sector: A Systematic Review. Computers \& Education, 138, 101-115.

https://doi.org/10.1016/j.compedu.2019.05.003

Lovreglio, R., Duan, X., Rahouti, A., Phipps, R., \& Nilsson, D. (2021). Comparing the Effectiveness of Fire Extinguisher Virtual Reality and Video Training. Virtual Reality, 25, 133-145. https://doi.org/10.1007/s10055-020-00447-5

Middleton, R. (2013). Active Learning and Leadership in an Undergraduate Curriculum: How Effective Is It for Student Learning and Transition to Practice? Nurse Education in Practice, 13, 83-88. https://doi.org/10.1016/j.nepr.2012.07.012

National Safety Council (NSC) (2021). OSHA Reveals Top 10 Violations for Fiscal Year 2020: Violations from Last Fiscal Year Remain at Top This Year.

https://www.nsc.org/newsroom/osha-reveals-top-10-violations-for-fiscal-year-202

Padilla, B. I., \& Kreider, K. E. (2018). Community of Inquiry Framework for Advanced Practice Nursing Students. The Journal for Nurse Practitioners, 14, e87-e92.

Pashler, H., McDaniel, M., Rohrer, D., \& Bjork, R. (2008). Learning Styles: Concepts and Evidence. Psychological Science in the Public Interest, 9, 105-119.

Poshdar, M., Zhu, Y., Ghodrati, N., Alqudah, H., Tookey, J., Gonzáles, V. A., \& Talebi, S. (2021). The Efficacy of Virtual-Reality Based Safety Training in Construction: Perceptions versus Observation. In ECPPM 2021-eWork and eBusiness in Architecture, Engineering and Construction: Proceedings of the 13th European Conference on Product \& Process Modelling (ECPPM 2021) (pp. 471-478). CRC Press. 
https://doi.org/10.1201/9781003191476-64

Ricci, F., Chiesi, A., Bisio, C., Panari, C., \& Pelosi, A. (2016). Effectiveness of Occupational Health and Safety Training: A Systematic Review with Meta-Analysis. Journal of Workplace Learning, 28, 355-377. https://doi.org/10.1108/JWL-11-2015-0087

Riener, C., \& Willingham, D. (2010). The Myth of Learning Styles. Change: The Magazine of Higher Learning, 42, 32-35.

Ruest, L. B., Svoboda, K. K., \& Opperman, L. A. (2017). Student Survey Results on the Integration of Active Learning Exercises in a Dental Education Self-Learning Setting. The FASEB Journal, 31, 576-613.

Satapanasatien, K., Phuawiriyakul, T., \& Moodleah, S. (2021). A Development of Game-Based Learning in Virtual Reality for Fire Safety Training in Thailand. In 2021 18th International Joint Conference on Computer Science and Software Engineering (JCSSE) (pp. 1-6). IEEE. https://doi.org/10.1109/JCSSE53117.2021.9493836

Traphagan, T. W., Chiang, Y. H. V., Chang, H. M., Wattanawaha, B., Lee, H., Mayrath, M. C. et al. (2010). Cognitive, Social and Teaching Presence in a Virtual World and a Text Chat. Computers \& Education, 55, 923-936. https://doi.org/10.1016/j.compedu.2010.04.003

Vidal-Gomel, C. (2017). Training to Safety Rules Use. Some Reflections on a Case Study. Safety Science, 93, 134-142. https://doi.org/10.1016/j.ssci.2016.12.001

Warner, A. G. (2016). Developing a Community of Inquiry in a Face-to-Face Class: How an Online Learning Framework Can Enrich Traditional Classroom Practice. Journal of Management Education, 40, 432-452.

Wiederman, M. (2015). Active Learning \& Learner-Centered Instruction. Learner-Centered Strategies. 